\title{
The technical research on advanced treatment and reuse of petrochemical sewage
}

\author{
Shuangchun Yang, Dan Deng, Min Yang, Si Li and Yi Pan* \\ Liaoning Shihua University, Fushun, China, 113001
}

\begin{abstract}
At present, many countries in the world are facing serious water crisis, the shortage of water in our country is particularly prominent, especially refining industry, water shortage and water pollution problems in our country have seriously affected the survival of enterprises and sustainable development. In this paper, based on literature research and field investigation, two stage discharging sewage of some petrochemical company was as our object. Feasibility research on the deep treatment and process unit effectiveness analysis was carried on, then a biological aerated filter and reverse osmosis system was put forward as the core (biological aerated filter-and inclined plate sedimentation-walnut shell filter-more medium filter-Filter-reverse osmosis systemsodium ion exchanger). The original process is very complicated and lengthy, but the new has a very strong special aim and a good impact resistance capacity, more reasonable process and more advanced technology.
\end{abstract}

Keywords: - sewage, advanced treatment, reuse, some petrochemical company

\section{INTRODUCTION}

Petrochemical wastewater contains a variety of impurities and its quality is large fluctuated. Especially sewage of processing heavy oil contains high oil contents and impurities, such as daub, ferrous sulfide, bacteria debris and so on. There are some natural emulsifiers such as gelatin, qualitative, organic acids and asphalt. Impurities mixed with natural emulsifier extremely become emulsification, and their formation is not a simple oil/ water [1] (O/W) or water/oil (W/O) system. Emulsification drop is made up of complex layers of water and oil, even salt and gas is in oil layer. Many suspended solids were carried in the process of oil production, and a variety of chemicals were blended in oil production and gas gathering process. In the exploitation of heavy oil, there are some organic pollutants such as phenol, naphthenic aromatic hydrocarbons, PAH and hydrocarbons. In summary, the oil recovery method, crude oil characteristics and geological conditions are different, so the oil refining sewage of water quality is different. As a result of petrochemical sewage quality is quite complex, the petrochemical sewage treatment needs the supply of fresh water, but the situation of water supply in our country is not optimistic at present. In addition to the enterprises along the Yangtze River water supply situation is better, the different degree of water shortage exists other regions. Especially in Shijiazhuang refinery, Cangzhou refinery, petrochemical company and oilfield enterprises only by overexploitation of groundwater to sustain production. Water resources have restricted the development of the northwestern of Urumqi petrochemical, Lanzhou oil refining factory and other enterprises for lacking of water, so they maintain the current production scale. North China's Yanshan petrochemical Company and northwest of Jinzhou petrochemical Company and other enterprises mainly rely on long-distance water conveyance to maintain production. Overall the majority of petrochemical enterprise in dry or severe water shortages regions needs large water consumption, and this causes large sewage water. Now the processing tons of oil sewage treatment amounts to $1.84 \mathrm{~m} 3$, this is 12.27 times than abroad, which led to the effect of China's petrochemical sewage can't be guaranteed, it pollutes environment and difficult to reuse, so far only individual enterprises realize the reuse of sewage in circulating water system. Aiming at the present situation of sewage treatment in petrochemical enterprise, good watersaving emission reduction technology and technical reformation is the key to solve water shortage situation. And greatly improve wastewater reuse rate is the main method to solve the water resource supply and demand contradiction of the enterprise.

\section{The Progress OF AdVANCEd Treatment OF REFINERy WASTEWATER AT HOME AND} ABROAD

\section{A. Activated Carbon Adsorption}

As the activated carbon has a good adsorption characteristic to dissolved organic matter. After granular activated carbon adsorption and secondary treatment, the content of Phenol, Oil, BOD5 of the wastewater close to the surface water standard, other indicators also be improved. The disabled saturated activated carbon can be reuse by regeneration [6]. The tertiary treatment of biological-activated carbon treatment process used the activated carbon adsorption may be more widely applied in the refinery, this process used biological treatment 
process to achieve the requirements of the refinery wastewater reuse, but the investment and operating cost much money [7].

\section{B. Ozone Oxidation}

Ozone as the tertiary treatment process is now rarely used at abroad, only some refineries in Canada and France use the method [8]. Some refineries in China had done the production test before [9], though the water quality can reach the surface water standard, they found that the investment and operating costs much more than the activated.

\section{Filtration}

General refineries usually use filtrations; it is the main method to remove the colloids and suspended matter in the wastewater after biological secondary treatment. It can be seen as the advanced treatment, and also can be as the pretreatment of activated carbon or ozone [10]. In recent years, with the development of the multilayer filter and polymeric coagulant was added as a filter, the filtration and treatment effect [11] were improved.

\section{Penetration}

In recent years, penetration in industrial wastewater has attracted widespread attention [12]. Many refineries are test and research the penetration at home and abroad. The scale from small-scale has been extended to semi-production. The processing capacity of semi-productive reverse osmosis device has reached 200 400 cubic meters per day. For example, Frankfurt airport uses reverse osmosis to handle groundwater, almost remove the contaminants in the groundwater. Durham introduced the long-term experience of the membrane reverse osmosis technology in wastewater treatment [13]; China describes the reverse osmosis technology and the development of factories in the Middle East [14].

In recent years, some advanced treatment method was developed, such as: membrane filtration method [15], [16] photochemical method (removal of toxic substances in industrial wastewater), UV oxidation method (removal of TCE pollution). In general, we can use many ways to meet the requirements of wastewater treatment and reuse. According to the purpose of reuse is different, its process can be divided into two stages, namely the preprocessing phase and post-processing stage for reuse requirements. The wastewater treatment meets the basic requirements of reuse process is preprocessing stage, and post-processing refers to the pretreated water according to reuse purpose of the special water quality control index for water quality control stage. For the two stages water, if you want to take it back to use as circulating cooling water, two stages of processing is necessary to meet the requirements of water quality of circulating cooling water.

About the sewage treatment technology, grease, flotation, biological treatment [17] (activated sludge $[18,19])$ and precipitate process, even only oil separation, filtration and other physical and chemical processes were initially used in foreign refining. Since the 70s, some ripe and advanced water treatment technology or process were used in oil refining wastewater treatment field, so that the treated effluent water quality is getting better and better. A/A/O process, anaerobic-aerobic biological treatment technology, oxidation ditch, sequencing batch reactor (SBR), biological filter, and biological fluidized bed has appeared in refinery sewage treatment system [20]. After 90s, the treated water quality can reach the standard of drinking water and reuse for the industrial production and life. Overall, the refinery wastewater [21] processing abroad using a variety of water purification technology, the process is long and have high wastewater reuse rate, but the treatment cost is very high.

The advanced treatment of sewage and reuse technology each has its characteristic, from the home and abroad development trend looks, ozone oxidation, reverse osmosis and activated carbon adsorption, electrodialysis, ion exchange method, chemical oxidation, membrane, and a combination of the above methods, as the new refinery sewage treatment technology to provide a good reference, to purify refinery wastewater and to achieve the discharge or reuse standard is quite valuable.

\section{A. Research Background}

\section{The InTroduce OF ORIGINAL Process}

Some petrochemical company is located in the sewage into the estuary national fishery water, Nature Reserve. The unique geographical position and the discharge environment decided the importance of the company's petrochemical sewage treatment discharge standards. In May of 2000 the city where the company located was officially named ecological construction demonstration area by the State Environment Protection Administration, local government is more stringent to the environment protection. In addition, as the processing scale, depth of processing and the proportion of super heavy oil processing are increasing; new chemicals are put into use. New device, especially delayed cooking unit go into operation, causing sewage emissions increased dramatically, up to 650 cubic meters per hour, and the water enter sewage field its quality is serious deterioration. Sometimes CODcr as high as $3000 \mathrm{~kg}$ per liter, the designed water capacity of original sewage 
plant is 300 cubic per hour, CODcr water is less than or equal to $1000 \mathrm{mg}$ per litre, the former is far beyond the design capabilities of the later. This study to the petrochemical subsidiary company chemical industry mixed wastewater after secondary biological treatment as the main research object, conduct the current investigation and analysis its water quality, according to request of the reuse water quality design process.

\section{B. Processing Status}

The company sewage-farm was built in 1979, designed by Changchun municipal administration designing institute and test run in 1980. After several times bigger reform, the sewage-farm adds Homogeneous pool, Life improve pump room, aero-tank, the inclined plate every oil pool and Filter sand processing system. Accident Pool was built considering the water coming impact, at the same time the company has set up three mud treatments incinerator to solve secondary pollution in sun sludge field. Now available handing ability is 300 cubic per hour. The technological process is shown in Figure 1.

The oily sewage from device area and each drainage point through the factory sewage pipe network, inspection shaft and flows through grilling well, and in the grilling well more than $25 \mathrm{~mm}$ big solid sundry were hold back, then enter collecting tank between lift pump.

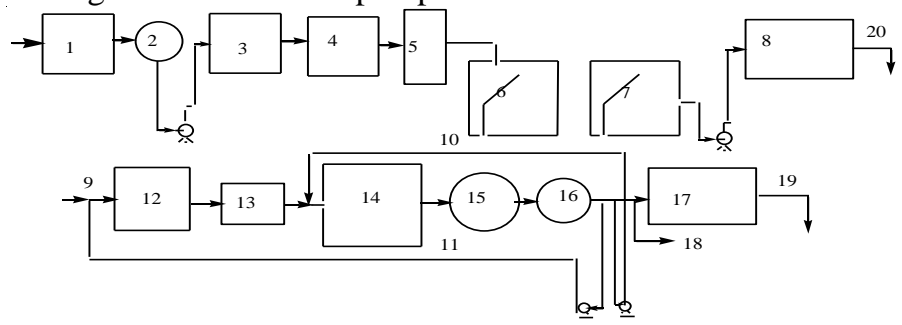

1. RETAINER. 2. SUMP. 3. A SEPARATE OIL POOL. 4. TWO SEPARATE OIL POOL. 5. INCLINED PLATE OIL SEPARATE TANK. 6. LEVEL 1 FLOTATION TANK. 7. LEVEL 2 FLOTATION TANK. 8. HOMOGENIZING POOL. 9. HOMOGENIZING TANK EFFLUENT. 10. SLUdGE RETURN. 11. InTERNAL RECYCLE. 12. $\mathrm{A}_{1} \cdot 13 . \mathrm{A}_{2} \cdot 14 \cdot \mathrm{O}_{1} \cdot 15 \cdot \mathrm{O}_{2} \cdot 16$. SeCONDARY SEDIMENTATION TANK. 17. SAND LEACH. 18. Sludge TO THREE MUD. 19. THE DRAINAGE. 20. TO A.

Figure 1. THE PROCESS FLOW DIAGRAM SEWAGE WORKSHOP

After the rank of pump room to ascend into a v-wind oil separator, into two v-wind oil separator, the inclined plate oil separator, mainly to remove the oil slick and suspended matter. Water oil content is controlled under $150 \mathrm{mg}$ per liter. Then flow into a flotation tank and two-flotation-tank, adding broken breast elixir, flocculating agents and help clotting agents before into the flotation pool. The flotation separation pool dissolves gas flotation, making the oil content is less than $20 \mathrm{mg} / \mathrm{l}$.

Among the ascension pump room ascension, into the homogeneous regulation ponds for homogeneous, then flows into anoxia biochemical basin (A), aerobic biochemical pool carbonization (O1), aerobic biological pool nitration pool $(\mathrm{O} 2)$, and make use of biochemistry method to remove the main organic pollutant as well as ammonia nitrogen in water. At last came into the second pond for active sludge precipitation and water separation.

Sand filter can handle the suspended matter and oily materials, then the water flows into efflux pumps and sump, after the ascension row to three-factory into crabs open ditch.

For the past two years, from some petrochemical refinery sewage operating data to see the water quality in sewage plant is large fluctuated. In October 2004 the effluent water quality is relatively good, but after the start of cooking workshop the sewage effluent water and into water quality is in general deterioration. After the start of cooking workshop sewage water and water monitoring data are show on Table 1 and Table 2.

TABLE 1: THE RECENT DATA OF A SEWAGE PLANT

\begin{tabular}{|l|l|l|}
\hline $\begin{array}{l}\text { Determination } \\
\text { Index }\end{array}$ & $\begin{array}{l}\text { The total entry average of } \\
\text { wastewater treatment plant }\end{array}$ & $\begin{array}{l}\text { Total effluent average of } \\
\text { wastewater plant }\end{array}$ \\
\hline PH value & 8.5 & 7.8 \\
\hline Oil content & 425.2 & 8.2 \\
\hline CORcr & 825.2 & 89.7 \\
\hline Sulfide & 7.41 & 0.32 \\
\hline Volatile phenol & 35.33 & 0.51 \\
\hline Ammonia nitrogen & 68.4 & 12.5 \\
\hline \hline
\end{tabular}


The technical research on advanced treatment and reuse of petrochemical sewage

TABLE 2: THE RECENT DATA OF TOTAL DRAINAGE ABOUT A PETROCHEMICAI COMPANYSEWAGE FIELD

\begin{tabular}{|l|l|l|l|}
\hline \hline Determination index & Average & Maximum & Minimum \\
\hline PH value & 8.6 & 11.3 & 4.3 \\
\hline Oil content & 679.2 & 8865 & 33 \\
\hline Sulfide & 2465 & 10180 & 328 \\
\hline Volatile phenol & 21.39 & 218 & 0.36 \\
\hline Ammonia nitrogen & 126.1 & 873.2 & 0.1 \\
\hline \hline
\end{tabular}

From monitoring data to see, water quality fluctuation and the impact problems are quite serious. Now the problems mainly existed in sewage plant are as following:

(1) With crude properties is changing and the process of oil refinery makes great progress, the discharge capacity of each process units and pollutant concentration are changed. But without corresponding process improvement, caused the impact of water quality of water yield, which leads to the biological treatment unit of activated sludge activity decline, and the treatment effect is worse. In October 2004, our company newly established and put 1 million tons per year's cooking units into production, this produced heavy oil wastewater discharge into sewage plant, leading to the activated sludge appeared for the unusual situation of death in large area. So the whole sewage plant is in a state of paralysis.

(2) Lacking of pretreatment facility and emergency measure. Because the ultra heavy oil is more, it produces the scum and sediment far beyond the processing capacity of "three" sludge treatment systems. The buffer capacity is lost, so when the big water and high concentration sewage is coming, processing system is no choice but to suffer impact.

(3) Cooking unit produces about 400 tons of ultra heavy oil wastewater every-day; the oil recovery is $90 \%$ to calculate, the lowest waste of oil resource may about 500 tons, about more than 150 ten thousand Yuan in economic losses. Because the ultra heavy oil causes sewage farm paralysis, so entrusting other sewage field is necessary.

Not only expensive processing fee and transportation, but also the big nature difference about ultra heavy oil wastewater and oil recovery, it is hard to handle. Along with the ultra heavy oil wastewater pretreatment project starting up, sewage plant monitoring data (shown as Table 3) shows that the situation greatly improved, but haven't reach the water requirements (shown as Table 4, Table 5).

TABLE 3: THE RECENT MONITORING DATA OF SEWAGE PLANT

\begin{tabular}{|l|c|c|}
\hline \hline Determinationindex & Average & Maximum \\
\hline PH value & 7.6 & 9.5 \\
\hline Oil content & 25.0 & 1328 \\
\hline CODcr & 363 & 5636 \\
\hline Sulfide & 0.44 & 17.2 \\
\hline Volatile phenol & 1.26 & 63.71 \\
\hline Ammonia nitrogen & 118.7 & 467.9 \\
\hline \hline
\end{tabular}


The technical research on advanced treatment and reuse of petrochemical sewage

TABLE 4: WATER QUALITY INDEXS OF ADD WATER CIRCULATION

\begin{tabular}{|c|c|c|c|c|}
\hline $\begin{array}{l}\text { Serial } \\
\text { number }\end{array}$ & Project & Unit & $\begin{array}{l}\text { China's oil water quality } \\
\text { index }\end{array}$ & $\begin{array}{l}\text { Water quality of some } \\
\text { petrochemical } \\
\text { office }\end{array}$ \\
\hline 1 & turbidity & NTU & $\leq 5$ & $<3$ \\
\hline 2 & petroleum & $\mathrm{mg} 1$ & $\leq 10$ & $<2$ \\
\hline 3 & CODMn & $\mathrm{mg} 1$ & CODcr $\leq 30$ & $<10$ \\
\hline 4 & CODcr & $\mathrm{mg} 1$ & $\leq 30$ & $<10$ \\
\hline 5 & Sulfate ( $\mathrm{SO} 4)$ & $\mathrm{mg} 1$ & $\leq 300^{-}$ & $\leq 150^{\circ}$ \\
\hline 6 & $\mathrm{NH} 3-\mathrm{N}$ & $\mathrm{mgl}$ & $\leq 3$ & $<5$ \\
\hline 7 & Total Fe & $\mathrm{mg} 1$ & $\leq 0.2$ & $<0.3$ \\
\hline 8 & $\begin{array}{l}\text { Total hardness(to } \\
\text { CaCO3) }\end{array}$ & $\mathrm{mg} 1$ & $\leq 150$ & $<100$ \\
\hline 9 & Heterotroph & 个 $/ \mathrm{ml}$ & - & $<500$ \\
\hline 10 & $\mathrm{sO42-}$ & $\mathrm{mg} 1$ & - & $<40$ \\
\hline 11 & ss & $\mathrm{mg} 1$ & $\leq 10$ & $<2$ \\
\hline 12 & Total alkalinity & $\mathrm{mg} 1$ & $\leq 150$ & $<100$ \\
\hline 13 & $\mathrm{PH}$ value & - & $6.5 \sim 8.5$ & $7.0 \sim 8.5$ \\
\hline 14 & $\mathrm{Ca} 2+$ & $\mathrm{mg} 1$ & - & 40 \\
\hline 15 & $\mathrm{Mg} 2+$ & $\mathrm{mg} 1$ & - & $10-30$ \\
\hline 16 & $\mathrm{Mn}$ & $\mathrm{mg} 1$ & $\leq 0.2$ & $\leq 0.2$ \\
\hline 17 & $\mathrm{Cl-}$ & $\mathrm{mg} 1$ & $\leq 200$ & $<75$ \\
\hline 18 & Totalphosphorus & $\mathrm{mg} 1$ & $\leq 1.0$ & $<0.5$ \\
\hline 19 & Totaliron & $\mathrm{mg} / 1$ & $\leq 0.2$ & $<0.3$ \\
\hline 20 & $\begin{array}{l}\text { Total dissolved } \\
\text { solid matter }\end{array}$ & $\mathrm{mg} 1$ & $\leq 800$ & $<350$ \\
\hline 21 & $\mathrm{SiO}_{2}$ & $\mathrm{mg} 1$ & $\cdots$ & $<10$ \\
\hline 22 & conductivity & $\mathrm{Hs} \mathrm{cm}$ & $800 \sim 1500$ & $<400$ \\
\hline
\end{tabular}

TABIE 5: THE WATER QUALITY OF BOILER FEED WATER

\begin{tabular}{|c|c|c|c|c|}
\hline $\begin{array}{l}\text { Serial } \\
\text { number }\end{array}$ & Project & Unit & $\begin{array}{l}\text { China's oil } \\
\text { water quality } \\
\text { index }\end{array}$ & $\begin{array}{l}\text { Water quality of } \\
\text { some petrochemical } \\
\text { brunch office }\end{array}$ \\
\hline 1 & turbidity & DTU & $\leq 0.3$ & 2 \\
\hline 2 & petroleum & $m g 1$ & 末棆测迁 & $\equiv 0.5$ \\
\hline $3^{-}$ & CODSIn & $m g r$ & $\equiv 2^{-}$ & 3 \\
\hline 4 & $\begin{array}{l}\text { Total } \\
\text { hardness(to } \\
\text { Caco } 3)\end{array}$ & $m g 1$ & $\leq 3$ & $=2.0$ ymol 1 \\
\hline 5 & $\begin{array}{l}\text { Total } \\
\text { alkalinity }\end{array}$ & $m g 1$ & $\leq 20$ & $\leq 1.0$ umol1 \\
\hline-6 & NHS-NT & $\bar{m} g 1^{-}$ & $\equiv 0.5$ & $\overline{-}$ \\
\hline-7 & conductivity & us $\mathrm{cm}$ & $\equiv 100^{\circ}$ & $\equiv 100^{\circ}$ \\
\hline 8 & $\mathrm{SiO}^{-}$ & $\operatorname{mg} 1$ & $\leq 0.4^{-}$ & $\equiv 0.1$ \\
\hline 9 & Nra & $m g r$ & $\leq 1 \mathrm{~s}$ & $\equiv 1^{-} 0^{-}$ \\
\hline 10 & Fe & $m g 1$ & $\$ 0.02$ & $\leq 30^{\circ}$ \\
\hline-11 & $\cos +$ & $m g 1^{-}$ & $\equiv 0.01$ & $\equiv 5^{-}$ \\
\hline 12 & chloride & $\operatorname{mg} 1$ & $\equiv 10^{-1}$ & $\cdots$ \\
\hline 13 & Pfivalue & $-\bar{x}$ & $6.5-7.2$ & $8^{-} \cdot 5-9.2^{-}$ \\
\hline
\end{tabular}


Deep treatment can be used at present industrialization process unit features, bio-filter, inclined plate setter, walnut filter, media filter were selected by research group to remove petroleum, COD, ammonia nitrogen target. In this paper analysis about the research as the object of study is stated in detail.

\section{Process OF Unit EfFectiveness Analysis UNIT}

Considering the growing tension of water resources and enterprises continuously pursue the way of reducing the cost of production, petrochemical wastewater recycling was put forward. The choice and combination of advanced treatment directly related to the success or failure of the sewage reuse, also connection to the economic and environment benefits, it is the key link of sewage reuse.

The choice of process fully considered discharge of wastewater quality routine analysis and the requirements of reuse water quality. Because the raw water as secondary biochemical drainage, the running situation of biochemical treatment system, operant level, the sewage category of biochemical system, the character and the climate make big difference on water quality index, the choosing of deep processing unit as follows: bio-filter, inclined plate setter, walnut filter, media filter, ultra filter, reverse osmosis system and sodium ion exchanger. Each of the deep treatment of the effectiveness of each unit analysis is as follows:

\section{(1)Biological aerated filters}

Biological aerated filter is one of biological membrane methods and treatments, when the waste water containing organic matter or suspension containing active sludge and a top-down through carrier medium, the suspended matter and microbial in water was absorbed in the solid media on the solid surface, some of the microbial make use of organic substrate to grow, and after a period the microbial forms a layer of mucous membrane in the surface of the carrier in appropriate circumstance. When wastewater contacts mucous membrane, the material exchange happened between solid and liquid. The microbial in biological membrane constantly growth and reproduction make use of membrane microbial activity, such as adsorption, decomposition of suspension, colloid and organic pollutant in wastewater. Biological aerated filters can be used as refinery sewage treatment to remove COD and ammonia nitrogen.

\section{(2) Plate sedimentation tank}

Aeration bio-filter out the water often has a variety of impurities, and with water forms sol mode of particles especially with impact load operation was not stable. Because Brownian motion and electrostatic repulsive force present settlement stability, usually the method of natural gravity settlement is unavailability to remove the suspension in wastewater. After adding flocculation to take off the firm, through the bridge adsorption effect, collide together and grow up for thick flocculating constituent. In order to improve the flocculation effect, organic polymer coagulant is necessary to added, making small loose flocculent body becomes bulky and be helpful for gravity settlement. The inclined plate sedimentation can be used to enhance the effect of settlement. The inclined plate sedimentation is a new sedimentation tank; it is designed by the shallow tank theory. There are many inclined plates in the settlement region, and water and suspended impurities flow on it in opposite direction. When wastewater flows up on the inclined plate, heavy suspended impurities will fall down in contrast, and the separated sludge slip to the bottom of the pool. The effect of inclined plate sedimentation settlement increased from 50\% to 60\%, and the processing capacity increased by from 5 to 6 times per unit area. This kind of sedimentation tank is economic and occupies small space.

\section{(3) Walnut shell filter}

The walnut shell filter is new filtering equipment apply to oily wastewater treatment. It uses a kind of walnut grain through a particular processing as the filter media. This filter media has characters as follow: high hardness, strong absorption capacity, when the oily wastewater flowing through the filter bed, the filter bed will absorb and closure the oil contamination and mechanical impurity, then the effluent with low oil containing will be obtained.

\section{(4) More medium filter}

More medium filter is a pressure filter used in water treatment frequently. Pore channel can formation by the gradation of quartz sand and anthracite, and it has the capacity bearing pollution. It's through the function of interception; precipitation and inertial force that make the suspended matter and colloid transfer and attach to the surface of filter, then reduce the SDI. As the pretreatment of the reverse osmosis system, more medium filter can remote the SS of the influent deeply and prevent the pollution of the system.

\section{(5) Reverse osmosis system}

Reverse osmosis system is a popular used process for removing ions. The pressure of the higher concentration side is higher than the other side's, water remove to the lower concentration side, while the solute 
will be intercepted. In this process, the remove and enrichment can be came true. Thanks to the tiny aperture, reverse osmosis membrane modules also can remove viruses, macromolecular organic compounds and small colloid. The departed subjects have no change in phase state in this process because it needn't to be heated. Reverse osmosis technology has become an indispensable technology in deep water treatment science it easy to operate, strong ability to apply and has no secondary pollution. Micro-filtration, use the static pressure difference as the impetus, is a new technology for sieve pore film separation. It is usually applied for intercepting the macromolecules and letting the small molecules pass through. Nowadays, ultra-filtration has been implemented in the water purification widely all over the world and has achieved a good effect. It can be used in the front of the system but also the end. It can prevent the particles entering to the product. This system often works under the pressure below $0.03 \mathrm{Mpa}$, and its filtering precision is $5 \mu \mathrm{m}$. Although fine filtering can't remove ammonia nitrogen and CODcr effectively, it can remove SS perfectly, so it can be used as the crucial step for removing the suspended.

\section{(6) Sodium ion exchanger}

Sodium ion exchanger is equipment can depart calcium and magnesium ions and then reduce the hardness according to the theory of ion exchange. Under certain pressure, when the sodium ions from resin can replace the calcium and magnesium ions in the water equally, the hardness will down. The purpose to setting a Sodium ion exchanger in this point is reducing the hardness of wastewater.

\section{(7) Spare pool}

The effluent of this engineering is a part of the source water for backwashing of rapid filter of some petrochemical company, thus this engineering often encounters a situation of water source shortage and high original water load. After a comprehensive explore, there is a spare pool in the engineering. At ordinary time, it can store the redundant water, while replenish in shortage time. Try to avoid the unstable of the whole system because of the fluctuations of the quality and volume of the water.

\section{CONCLUSION PRocess DeSIGN}

A conclusion section must be included and should indicate clearly the advantages, limitations, and possible applications of the paper. Although a conclusion may review the main points of the paper, do not replicate the abstract as the conclusion. A conclusion might elaborate on the importance of the work or suggest applications and extensions.

When we choose an advanced treatment process, many elements must be taken into account. Such as: the usage of the effluent, the way and target of recycling, corrosion, scaling and biological slime.

Raw water of this technology is the effluent of secondary treatment, and the product water is boiler soft-water $(160 \mathrm{~m} 3 / \mathrm{h})$ and added water in recycling $(200 \mathrm{~m} 3 / \mathrm{h})$.

What's more, economic factors is one of the elements must be considered. Taking full use of the equipment available, in order to reduce the fee for operation and maintenance.

In Figure 2, the fittest technological process by analyzing the validity of each part and the elements

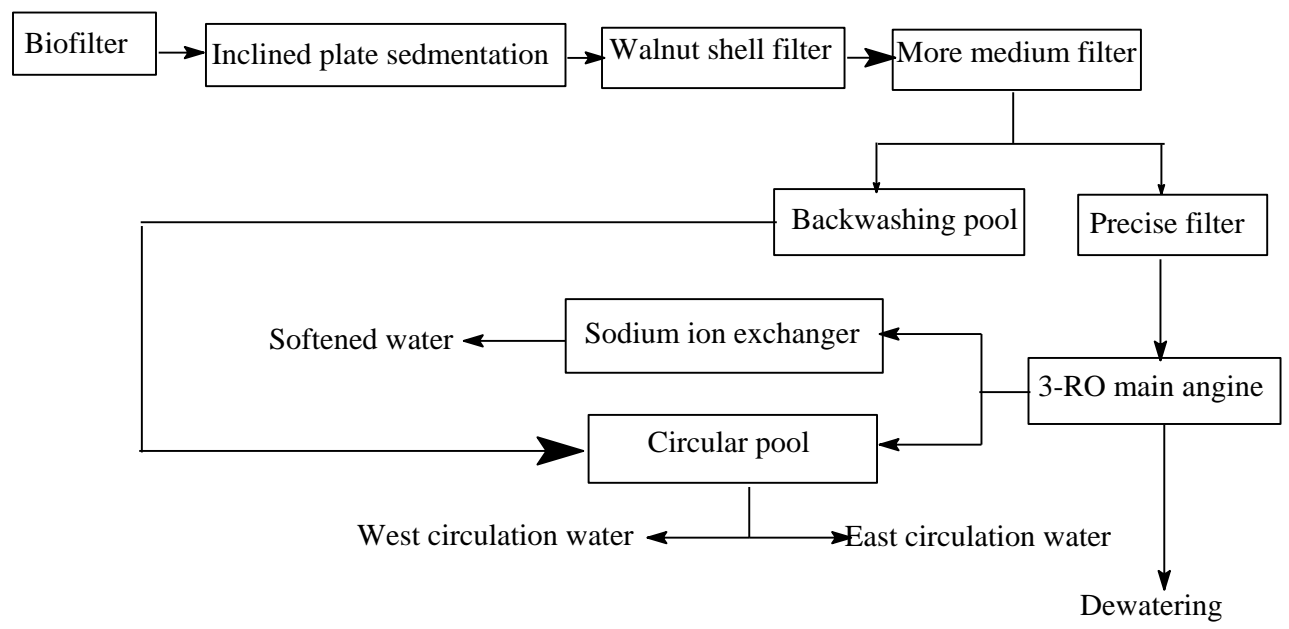

influent the system are listed. 
The design of water soften is: Secondary emission water + Biofilter + Inclined plate sedimentation + Walnut shell filter + More medium filter + Precise filter + Reverse osmosis system + Sodium ion exchanger;

The design of water circulation is: Secondary emission water + Biofilter + Inclined plate sedimentation + Walnut shell filter + More medium filter + Precise filter + Reverse osmosis system.

When compared with other water circulation process, this process has these characters:

1. Easy to control and maintain, occupying small space.

2. Strong adaptability for the change of the quality and volume of the water.

3. Reverse osmosis system uses the antipollution membrane modules because they have wide channel and easy to clean. Increasing the number of membrane modules can decrease the membrane flux per area and the frequency of blocking; this measure can protect the system from the influence of water volatility. Precise filter is set for downing the pollution bearing of membrane modules.

A pilot scale test at a treatment scale of $400 \mathrm{~m} 3 /$ a should be done to design the application. For the requirement of anticorrosion, all application must be made of stainless steel except to wastewater tanks outdoor, microfiltration and ultra-filtration equipments. And the wastewater tanks outdoor was made of anticorrosion carbon steel, microfiltration and ultra-filtration equipments are made of plastics. The names and functions are in the Table 6 . The process flow is in the Figure 3.

Table 6: THE FLOW REACTOR EQUIPMENT LIST

\begin{tabular}{|c|c|c|}
\hline $\begin{array}{c}\text { Serial } \\
\text { number }\end{array}$ & Device Name & Main application \\
\hline 1 & The original water tank & Raw water reverse \\
\hline 2 & Biofilter & Suspended matter and microorganism in water \\
\hline 3 & Inclined plate settler pool & Impurities settlement \\
\hline 4 & Walnut shell filter & The desorption of oil and suspended matter \\
\hline 5 & More medium filter & Removal the water suspended matter in depth \\
\hline $6^{-}$ & Ultra-filter & Removal the suspended in depth \\
\hline 7 & Reverse osmosis system & Advanced treatment \\
\hline 8 & Sodium ion exchanger & Water quality drop hard softening \\
\hline $9^{-}$ & Circular pool & Store excess discharge \\
\hline $10^{-}$ & Relay tank & Flow adjusting buffer \\
\hline
\end{tabular}
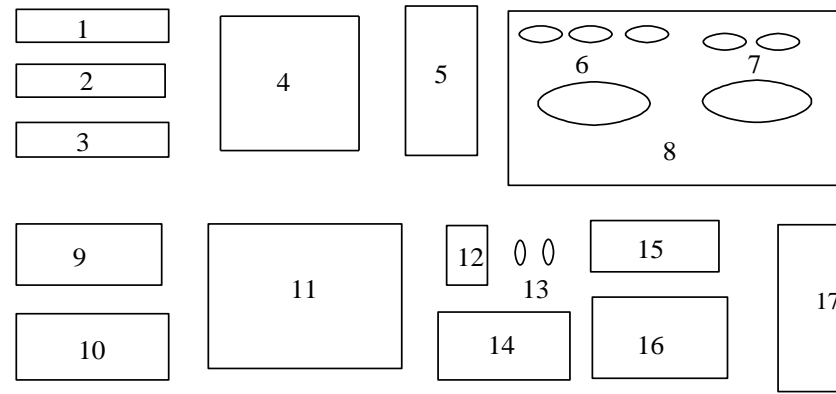

\begin{tabular}{|c|c|c|c|c|c|c|}
\hline$\left|\begin{array}{c}\text { des } \\
\mathrm{i} \\
\mathrm{gn}\end{array}\right|$ & \begin{tabular}{l|l} 
xiao & examine \\
chen & and \\
Wang venrify
\end{tabular} & $\begin{array}{l}\text { Zhang } \\
\mathrm{Li}\end{array}$ & $\mid \begin{array}{l}\mathrm{da} \\
\mathrm{ta}\end{array}$ & \begin{tabular}{l|c}
2 & examin \\
0 & and \\
0 & and \\
6 & venrify
\end{tabular} & \begin{tabular}{c|c}
$\mathrm{Li}$ & $\mathrm{da}$ \\
$\mathrm{Li}$ & $\mathrm{ta}$
\end{tabular} & 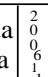 \\
\hline & he Petroche & $1 \mathrm{Cc}$ & & item & $\begin{array}{l}\text { depth } \\
\text { proces } \\
\text { recycl }\end{array}$ & $\begin{array}{l}\text { ssing } \\
\text { cling }\end{array}$ \\
\hline
\end{tabular}

Note: 1.biological aerated filter A. 2.biological aerated filter B. 3.biological aerated filter C. 4.inclined plate setter pool. 5. Circulating water added pool. 6. Walnut shell filter.7.sodium ion exchanger.8.more medium filter. 9. Spare pool. 10. The floor area of original equipment. 11. The floor area of original equipment.12. RO pump. 13. Dosing pump. 14. The floor area of original equipment. 15. RO system. 16. Distribution room. 17.

The floor area of original equipment.

\section{FIGURE3. THE APPERANCE OF CHEMICAL PROCESS}


The result of pilot scale test reveals that this process is a successful technology for advanced water treatment. It is more economic than other technologies, such as, desorption nitrogen process, breakpoint adding chlorine process and blow-off technology. It is stable, simple and cheap. This technology can product desalted water by reverse osmosis membrane, and send it to low pressure boiler. Through the primary treatment this process can product reclaimed water as cycle water. These can save freshwater and reduce the fee for buying freshwater and discharging wastewater.

\section{Conclusions}

This technology contains the processes of physical, chemical, and biological though the flow is simple. It has a strong pertinence and every application in it has its own objective. In comparison to other technologies dominated by filtration, this technology is more reasonable and advancing. A further industrialization experiment is needed for this technology apply to practice as soon as possible.

\section{Acknowledge}

This research work was form contract which number is 201101.01.79.

\section{REFERENCES}

[1] Weiyu Fan, Yuanming Song, Guozhi Nan·"The stability water bag heavy oil emulsion"·Journal oil(petroleum proces sing), vol. 17. pp 1-2. 2001.

[2] Lu Shuguang An Tingnian Expeiment on ozone treatment of Jizhuangzi Wastewater treatment plant secondary effluent [J]. Zhongguo jishi Pashui, 12(4),pp 34-35, 1996.

[3] Jorgensen KS. Puustinen J. Suortli AM. Bioremediation of petroleum hydrocarbon contaminated soil by composing in biopiles [J] Environment Pollution, 107: pp 245-254, 2000.

[4] Lin Q Mendelsson I A The combied effects of phytoremediation and biostimulation in enhancing habitat restoration and oil degradation of petroleum contaminated wetlands [J] Ecological Engineering, 649,pp 196-210,1996,

[5] Jimei Zhang, Lihua Tong, Xianfeng Pan, "The experimental research Standard about oil refinery sewage reuse" corrode and fence about petrochemical industry vol 23(3), pp 50-52, 2006.

[6] Lishan Zhang, Yufen Zhang, Flocculation processing oil field research and application status of the waste water, Hebei Industrial technology vol 22(6), pp 361-165, 2005.

[7] Xianting Meng, Zhenjia Meng, “Active carbon adsorption and microbial regeneration”. Water Treatment technology. vol. 13(3). pp. 174-180. 1987.

[8] Newcomb G Collett A Granular activated carbon pilot plant studies[J]. Water Supply, 23(6),pp 29-31,1996

[9] Bonnelye V Richard Y Changes in ozone demand of water during the treatment process. Ozone Sci. Eng, 19(4),339-350,1997.

[10] Qiding Bao, Ozone cooling water treatment industrial water cooditioning, vol 12(2), pp 3-9, 1992.

[11] Jigang Zhang, The refinery sewage reuse technology research, modern chemical industry, vol 34(4), pp 266-272, 2005.

[12] Daorong Cai, Yonghui Yu, Jinyi Wang, Coagulation floating-filtering method processing oilfield ultra heavy oil wastewater, Environmental pollution and prevention, vol 28(7), pp 519-530, 2006.

[13] Jorgensen KS. Puustinen J. Suortli AM. Bioremediation of petroleum hydrocarbon contaminated soil by composing in biopiles [J] Environment Pollution,107,pp245-254,2000.

[14] Rilley A P, Banks M K Dissipation of PAHs in the rhizosphere [J]. Journal of Environment Quality, 25,pp 212-219,1996.

[15] Liste H H Alexandar M Plant-promoted pyrene degradation in soil [J] Chemophere.40,pp 7-10,2000.

[16] Lehui Zhu, The present situation and the development about Activated sludge process, Environment and develop, vol 12(1), pp 9-12, 1997.

[17] Shucheng Lan, Activated carbon water treatment technology, China environmental science press, Beijing, pp 94-124, 1991.

[18] Qunbiao He, Jining Qu, Hongbin Chen, The technology research progress about sewage reuse and advanced treatment, Industrial water treatment, vol 30(10), pp 62-63, 2002.

[19] [19] Xianting Meng, Active carbon adsorption and microbial regeneration, Water treatment technology, vol 13(3), pp 7-14, 1987.

[20] Yali Zhan, Shaohui Guo, Jianlin Wang, sewage organic composition and coagulation treatment after the oil refinery, environment protection about the oil and gas field,vol 12(4), pp 10-12, 2002.

[21] Caihong Yu, Jun Jiao, technology research about refinery sewage reuse, Liaoning urban and rural environmental science and technology, vol 22(1), pp 12-15, 2002. 